\title{
Evaluation of Surgeon's Exposure to Formaldehyde, PM 2.5, and Volatile Organic Compounds
}

\author{
Rohan Jadhav, PhD, MPH ${ }^{* *}$, Chandran Achutan, PhD , $\mathrm{CIH}^{2}$ \\ ${ }^{1 *}$ Assistant Professor, Department of Public Health, College of Health and Human Services, California State University, Fresno, CA, USA. \\ ${ }^{2}$ Associate Professor, College of Public Health, University of Nebraska Medical Center, Omaha, NE, USA.
}

\author{
Article Details \\ Article Type: Research Article \\ Received date: $27^{\text {th }}$ November, 2020 \\ Accepted date: $21^{\text {st }}$ December, 2020 \\ Published date: $23^{\text {rd }}$ December, 2020
}

"Corresponding Author: Rohan Jadhav, PhD, MPH, Assistant Professor, Department of Public Health, College of Health and Human Services, California State University, Fresno, CA, USA. E-mail: rjadhav@mail.fresnostate.edu

Citation: Jadhav, R. \& Achutan, C. (2020) Evaluation of Surgeon's Exposure to Formaldehyde, PM 2.5, and Volatile Organic Compounds. J Pub Health Issue Pract 4(2): 172. doi: https://doi.org/10.33790/jphip1100172.

Copyright: $\mathbb{C} 2020$, This is an open-access article distributed under the terms of the Creative Commons Attribution License 4.0, which permits unrestricted use, distribution, and reproduction in any medium, provided the original author and source are credited.

\begin{abstract}
Background and Objectives: Electrocautery is an essential tool in surgery used for dissecting tissue layers and to control bleeding. Health risks from the exposure to surgical smoke are not completely understood. The purpose of this study was to measure the extent of exposure to chemicals present in surgical smoke during surgery.

Method: Personal air monitoring of known carcinogens such as formaldehyde and volatile organic compounds (VOCs) and real-time area monitoring of PM 2.5 particles originating from electrocautery use was conducted during a live surgery. A quantitative survey was administered to surgeons in a medical center to assess the exposure and health effects related to surgical smoke. Personal air monitoring was achieved by measuring the concentration of formaldehyde and VOCs from passive samplers placed on surgeons' caps. A particle counter was used to monitor the concentration of PM 2.5 particles in the surgical field. A health symptoms questionnaire was collected from 43 surgeons in a medical center located in a Midwestern state.

Results: A low but detectable level of formaldehyde was reported from sampled data during personal exposure monitoring. The mean concentration of PM 2.5 particles during the active use of electrocautery period was $795 \mu \mathrm{g} / \mathrm{m}^{3}$ and was far greater than background and post-exposure concentrations. The irritation of upper respiratory mucosa after the use of electrocautery were commonly reported in the survey.
\end{abstract}

Conclusion: The study was highlighted by the detectable presence of formaldehyde in personal environment. Future research should explore cause-and-effect relationship of occupational exposure to surgical smoke at low levels.

\section{Introduction}

Electro-cautery is an important tool in surgery. It is used to dissect through tissues and coagulate blood vessels in order to reduce blood loss and operation time [1]. Electrocautery achieves coagulation by transfer of electro-surgical energy to the tissues from the electrocautery device, vaporization of the cellular fluid and rupture of the cellular membrane. These events cause release of intense heat that burns the proteins and other organic matter in the cell. The burning of cellular contents leads to charring of cells that creates surgical smoke [2]. Surgical smoke consists of $95 \%$ of water vapor and five percent of particulate matter. The particulate matter is composed of chemicals, blood and tissue particles, viruses and bacteria [3].
Studies have reported transfer of viable biological pathogens from electrocautery to healthcare staff $[4,5]$.

Hazards of surgical smoke have been documented in the scientific literature [2]. Surgical smoke has been reported to have strong smell, and causes headache and irritation of eyes, throat and skin [6]. Some of the common chemicals in surgical smoke include volatile organic compounds (VOCs) such as benzene, toluene, styrene, ethyl benzene; aldehydes such as formaldehyde, acetaldehyde, acetone, butanol, benzaldehyde; polycyclic aromatic hydrocarbons; acrylamide; and inorganic gases such as carbon dioxide, carbon monoxide, and sulfur dioxide $[3,7]$. Manyof these chemicals are carcinogenic.

The practical risk from exposure to surgical smoke is still not clear and currently there is no recommended standard for chemicals originating from surgical smoke [8]. Surgical masks do not provide sufficient protection against ultra-fine particles $[6,9]$. High quality engineering control methods such as smoke evacuation system using high efficiency particulate air filters, general room and local exhaust ventilation systems with exchange rate of $20 /$ hour $[10,11]$ and administrative controls [11] have been recommended to manage surgical smoke exposure. The exposure to surgical smoke is greater in laparoscopy procedures compared to that from open surgery. The reason is that the much concentrated smoke is released from the cannula of the laparoscope compared to smoke during open procedures, and the surgical smoke released in the operation room all at once to the surgical staff closer to the jet of the cannula [9]. The surgical smoke is concentrated in laparoscopic procedures because the surgical smoke has no place to go other than when the jet of cannula is taken out from the operation site while in open procedures the smoke can disperse into operation room in real time.

The objective of this study was to describe the exposure of surgical smoke to surgeons during live surgery. The specific aims of this study were 1) to evaluate surgeons' long-term health effects from the use of surgical smoke using a self-administered survey, 2) to measure levels of fine particulates (PM 2.5) using area monitoring, and 3) to evaluate surgeons' exposure to formaldehyde and volatile organic compounds such as benzene and toluene during a live surgery session. The study was approved by the institution's review board for the protection of human subjects.

\section{Methods}

The study was done in the two phases. During the first phase, a health 
symptoms questionnaire was administered to surgeons, and in the second phase, exposure to selected chemicals in surgical smoke was monitored during one live surgery session. Both authors were present during the monitoring session.

Study questionnaire: Surgeons who use both laparoscopic and open procedures were considered for the study. No restrictions were placed on demographic variables such as age, gender, race, ethnicity, and years of experience in surgery, board certifications and surgical specialty. A quantitative anonymous online study questionnaire was disseminated to 200 surgeons employed in a medical center located in the Midwestern region of the United States. Surgeons from different surgical specialties perform different routine procedures. We were interested the manner (open vs. laparoscopic) by which the most routine procedures were performed regardless of surgical specialty. The questionnaire also included frequency of electrocautery use (0-20 times, 21-40 times, 41-50 times, 61-80 times, and $\geq 81$ times), history of infection from electrocautery smoke, health symptoms associated with the use of electrocautery, and use of personal protective equipment. We included nine close-ended questions and two openended questions. The questionnaires were sent electronically to surgeons' email addresses by SurveyMonkey software [12]. The SurveyMonkey software was also used to collect the responses and the descriptive data was analyzed in Microsoft Excel.

Personal exposure monitoring: We evaluated surgeons' exposures to VOCs and formaldehyde for one live surgery session; asarcoma resection of liver surgery withan open procedure. Passive samplers were used to sample for VOCs (benzene and toluene), and formaldehyde, from surgical smoke. The VOCs were sampled by the SKC Ultra Passive Diffusive Sampler [13]; from here onwards referred asthe VOC badge. Formaldehyde was sampled by the UMEX Diffusive Sampler [14]; from here onwards referred as the formaldehyde badge.

Because of the risk of contamination of open badges from arm movements or accidental touching, the passive samplers were not placed on surgeon's collar at the neckline area, a preferred site for personal breathing zone (0.3 meters from nose and mouth) [15]. Therefore, the VOC and formaldehyde badges were placed on the front end of the surgical cap/helmet of surgeons/residents for the duration of surgery and this placement site was consistent with the breathing zone parameter. The badges were operated per manufacturer's instructions. Field blanks of VOC and formaldehyde samples were treated the same way as the test samples. VOC and formaldehyde badges were analyzed by an accredited laboratory. VOC samples were analyzed per the National Institute for Occupational Safety and Health (NIOSH) Method \# 2549 and formaldehyde samples were analyzed per NIOSH Method \# 2016 [16, 17].

Area monitoring: Area monitoring of PM 2.5 commenced at the same time as of personal exposure monitoring. We used factorycalibrated Thermo Scientific Personal Data Ram monitor (PDR-1500) with SCC 1.062 cyclone to filter $50 \%$ cut off mass median dimeter of PM 2.5 [18]. As per the manufacturer'smanual, factory calibration of PDR-1500 is conducted using International Organization for standardization approved fine dust with mass median dimeter of 2-3 $\mu \mathrm{m}$, geometric standard deviation of 2.5 , bulk density of 2.60 to $2.65 \mathrm{~g} / \mathrm{cm}^{3}$ and the refractive index of 1.54 [18]. The PDR-1500 instrument was zeroed before area monitoring was conducted using the method of recirculation of the exhaust air into the inlet [18]. A 3-foot sampling tube was connected to this assembly and the other end of the tube was suspended in the surgical field upon sanitization. A surgical field is a sterile field which consists of a draped patient on the operation table in the center of the field and autoclaved or sealed surgical instruments and supplies on a trolley, and surgery personnel with sterile personal protective equipment (PPE) such as surgery caps, goggle, and gowns and gloves- remain on the periphery of the surgical field. Non-sterile equipment and personnel without sterile PPE protection cannot enter the surgical field.

J Pub Health Issue Pract

Volume 4. 2020. 172
The authors stayed outside of the surgical field and operated the PDR-1500 equipment. The time at which the sampling equipment was turned on until the first use of electrocautery served as background exposure time.The sampling was continued until the end of surgery. The data was logged into the PDR-1500 instrument and the logging averaging period was set at one second. The entire surgery lasted for 158 minutes. The time after the last use of electrocautery until the end of surgery served as post-exposure concentration period. Other potential confounding sources of particulate exposure such as saline mist, laser equipment or sonographic ablation knife were not used during the surgery. We also observed for surgeon's coughing and sneezing episodes during electrocautery use.

Data analysis: The survey responses were analyzed and frequencies for the survey responses were generated. The logged PM 2.5 data was exported to Microsoft Excel. Descriptive statistics (mean, standard deviation and maximum and minimum values) of PM 2.5 samples obtained from the area monitoring were analyzed in Statistical Analysis System version 9.3 [19].

\section{Results}

The questionnaire was sent out to approximately 200 surgeons working in different capacities such as faculty members, residents and attending surgeons. A total of 43 surgeons filled out the questionnaire for a response rate of $21 \%$.

As seen in Table 1, the overall frequency of open, laparoscopic and both procedures for the top five routine operative procedures was 32 (72\%), $32(16 \%)$ and $22(11 \%)$ respectively. The surgeons preferred open procedures over laparoscopic and both.

The frequency of electrocautery use for all five procedures obtained from the survey is shown in Table 2. The overall frequency for the use of cautery 21-40 times was 92 (47\%) and was the highest among other categories. The frequency of use of cautery in the $0-20$ category was $56(28 \%)$ and was the second highest. The frequency of electrocautery use was 11 times for our monitored surgery session.

The frequency of respiratory diseases in surgeons is reported in Table 3. The frequency of presence of symptoms was 14 (8.4\%) from the total of 166 responses for all respiratory diseases. Specifically, asthma was the most common disease reported by surgeons with frequency of $21.4 \%$. More than $7 \%$ of the surgeons reported bronchitis.

The overall frequency of the presence of symptoms in surgeons after the use of cautery was $38(10 \%)$. As illustrated in Figure 1, among the surgeons who reported the presence of symptoms, the most common symptom reported was eye irritation $(21.4 \%)$. Headache was the second most common symptom (12.2\%).

At least one anonymous response (2.5\%) for the open ended question about the history of infection of pathogens from the surgical plume was positive for the spread of of human papilloma virus (HPV) and that it caused a facial lesion.

Table 4 reflects the distribution of responses pertaining to the frequency of use PPE. The majority of the surgeons reported that they always used PPE of some kind. The use of surgical mask, gown and gloves wasthe commonest with frequencies of 37 (92.5\%), 38 (95\%) and $36(90 \%)$, respectively. No use of $\mathrm{N}-95$ respirator was reported in the operation room. In response to open-ended questions, a few surgeons said that they use protective eye gear and smoke aspirators.

The concentration of particulates at background, between the first and final use of electrocautery (exposure period), and during postexposure period is shown in Table 5. The mean background and post-exposure concentration were similar $\left(2.38\right.$ and $\left.3.76 \mu \mathrm{g} / \mathrm{m}^{3}\right)$, suggesting the optimal clearance of particulates by the operation 


\begin{tabular}{|l|l|l|l|}
\hline Procedure & Open & Laparoscopy & Both Open \& Laparoscopy \\
\hline Procedure 1 & $32(76.19 \%)$ & $6(14.29 \%)$ & $4(9.52 \%)$ \\
\hline Procedure 2 & $26(66.67 \%)$ & $6(15.38 \%)$ & $7(17.95 \%)$ \\
\hline Procedure 3 & $30(75.00 \%)$ & $6(15.00 \%)$ & $4(10.00 \%)$ \\
\hline Procedure 4 & $26(70.27 \%)$ & $6(16.22 \%)$ & $5(13.51 \%)$ \\
\hline Procedure 5 & $28(73.68 \%)$ & $8(21.05 \%)$ & $2(5.26 \%)$ \\
\hline
\end{tabular}

Table 1 . The method of conduction of the chosen routine procedures reported by surgeons

\begin{tabular}{|l|l|l|l|l|l|}
\hline Procedure & 0- 20 times & $\mathbf{2 1 - 4 0}$ times & 41- 60 times & $\mathbf{6 1 - 8 0}$ times & More than 80 times \\
\hline Procedure 1 & $12(29.27 \%)$ & $18(43.90 \%)$ & $5(12.20 \%)$ & $0(0 \%)$ & $6(14.63 \%)$ \\
\hline Procedure 2 & $11(27.50 \%)$ & $19(47.50 \%)$ & $4(10 \%)$ & $1(2.50 \%)$ & $5(12.50 \%)$ \\
\hline Procedure 3 & $10(26.32 \%)$ & $18(47.37 \%)$ & $4(10.53 \%)$ & $1(2.63 \%)$ & $5(13.16 \%)$ \\
\hline Procedure 4 & $11(28.95 \%)$ & $19(50.00 \%)$ & $2(5.26 \%)$ & $1(2.63 \%)$ & $5(13.16 \%)$ \\
\hline Procedure 5 & $12(31.58 \%)$ & $18(47.37 \%)$ & $3(7.89 \%)$ & $0(0 \%)$ & $5(13.16 \%)$ \\
\hline
\end{tabular}

Table 2. The frequency of electrocautery use for top five chosen routine procedures reported by surgeons

\begin{tabular}{|l|l|l|}
\hline Respiratory Disease & Yes & No \\
\hline Asthma & $9(21.43 \%)$ & $33(78.57 \%)$ \\
\hline Bronchitis & $3(7.14 \%)$ & $39(92.86 \%)$ \\
\hline Chronic Obstructive Pulmonary Disease (COPD) & $1(2.44 \%)$ & $40(97.56 \%)$ \\
\hline Emphysema & $1(2.44 \%)$ & $40(97.56 \%)$ \\
\hline
\end{tabular}

Table 3. Frequency of respiratory illnesses reported by surgeons

\begin{tabular}{|l|l|l|l|l|}
\hline Personal Protective Equipment & Never & Seldom & Usually & Always \\
\hline Surgical Mask & $0(0 \%)$ & $1(2.50 \%)$ & $2(5.00 \%)$ & $37(92.50 \%)$ \\
\hline N-95 Respirator & $30(78.95 \%)$ & $8(21.05 \%)$ & $0(0 \%)$ & $0(0 \%)$ \\
\hline Gloves & $2(5.00 \%)$ & $0(0 \%)$ & $0(0 \%)$ & $38(95.00 \%)$ \\
\hline Gown & $1(2.50 \%)$ & $0(0 \%)$ & $3(7.50 \%)$ & $36(90 \%)$ \\
\hline Other & $5(38.46 \%)$ & $0(0 \%)$ & $0(0 \%)$ & $8(61.54 \%)$ \\
\hline
\end{tabular}

Table 4. Frequency of the use of personal protective equipment by surgeons

\begin{tabular}{|l|l|l|l|l|}
\hline Exposure phase & Mean $\left(\boldsymbol{\mu g} / \mathbf{m}^{3}\right)$ & Standard Deviation $\left(\boldsymbol{\mu g} / \mathbf{m}^{3}\right)$ & $\begin{array}{l}\text { Minimum value } \\
\left(\boldsymbol{\mu g} / \mathbf{m}^{3}\right)\end{array}$ & $\begin{array}{l}\text { Maximum value } \\
\left(\boldsymbol{\mu g} / \mathbf{m}^{3}\right)\end{array}$ \\
\hline $\begin{array}{l}\text { B a c k g r o u n d } \\
\text { exposure }\end{array}$ & 2.39 & 1.18 & 1.01 & 12.03 \\
\hline Exposure Peak 1 & $3,855.93$ & $6,181.36$ & 18.13 & $22,002.05$ \\
\hline Exposure Peak 2 & $2,285.62$ & $3,120.21$ & 14.74 & $9,618.51$ \\
\hline Exposure Peak 3 & $5,255.52$ & $7,788.65$ & 37.58 & $26,590.36$ \\
\hline Exposure Peak 4 & $6,814.93$ & $5,548.94$ & 93.63 & $19,695.10$ \\
\hline Exposure Peak 5kk & $1,769.84$ & $3,977.56$ & 6.67 & $15,364.43$ \\
\hline Overall exposure & 795.80 & $2,947.16$ & 2.54 & $26,590.36$ \\
\hline Post-exposure & 3.76 & 1.46 & 1.01 & 24.47 \\
\hline
\end{tabular}

Table 5. The concentration of PM 2.5 in $\mu \mathrm{g} / \mathrm{m}^{3}$ released during the live surgery session during background, exposure and post-exposure phase is shown. The mean, standard deviation, maximum and minimum values for PM 2.5 are displayed. 


\section{Frequency of Health Symptoms}

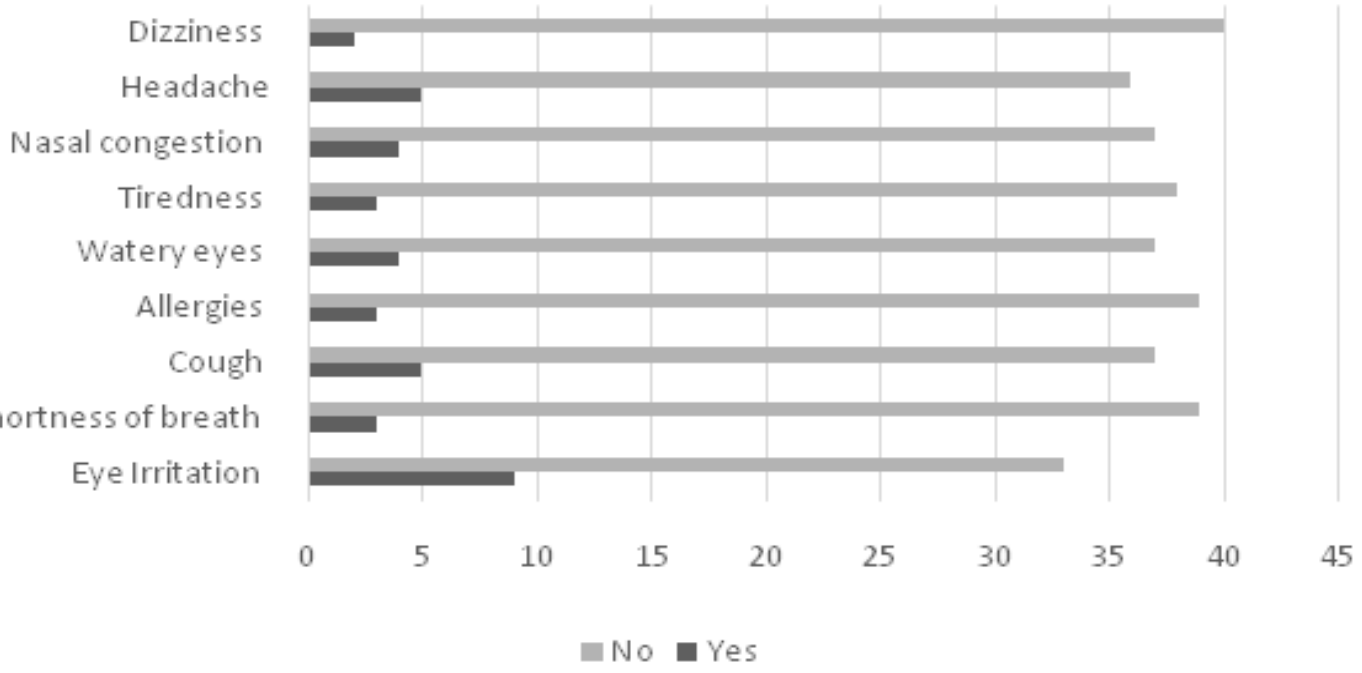

Figure 1. Results of responses to the health symptoms experienced from electrocautery use

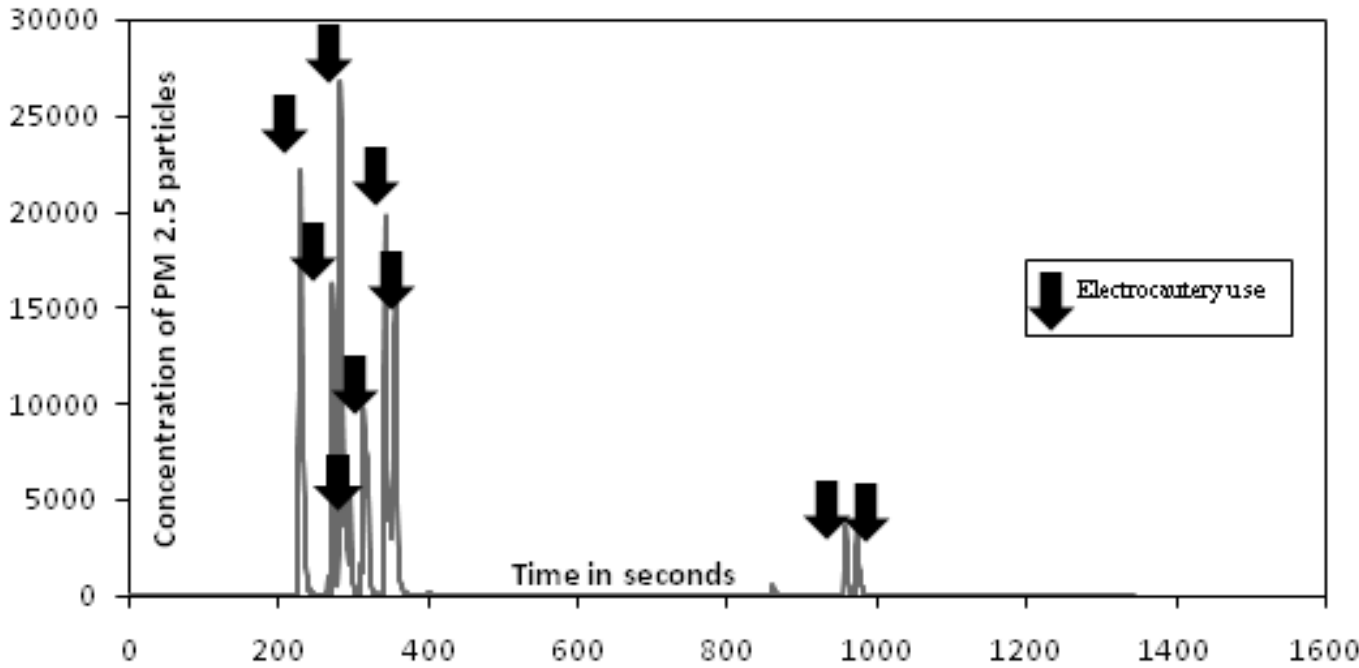

Figure 2. Distribution of PM 2.5 originating from electrocautery use during the duration (in seconds) of live surgery. The peaks reflect the concentration of surgical smoke (in $\mu \mathrm{g} / \mathrm{m}^{3}$ ) during each use of electrocautery.

A time-series plot showing the distribution of PM 2.5 sampled from monitored surgery sessionis illustrated in Figure 2. It provides a snapshot of the total of 158 minute-long surgery. The concentration of PM 2.5 increased to very high levels (as high as $26,590 \mu \mathrm{g} / \mathrm{m}^{3}$ ) during the use of electrocautery. After electrocautery use, the concentration of particulates returned to low levels $\left(\leq 10 \mu \mathrm{g} / \mathrm{m}^{3}\right)$ within the range of 12-90 seconds. The mean concentration of PM 2.5 during the five selected exposure peaks is depicted in Table 5. These clusters represent very high PM 2.5 levels during electrocautery use.

In the 158 minute-long surgery, the total time of electrocautery use was 6.61 minutes. The background and post exposure of PM 2.5 was minimal compared to the PM 2.5 exposure during surgery indicating high ventilation system efficiency in the operation room.

Adetectable, but low level of formaldehyde ( 9.3 parts per billion) was measured during personal exposure monitoring. Volatile organic compounds were not detected.

\section{Discussion}

This study focused on two known carcinogens, VOCs and formaldehyde; and a respiratory irritant, PM 2.5. Benzene is linked to the development of aplastic anemia, acute leukemia and bone marrow abnormalities [20]. Many VOCs are present in the smoke generated by combustion of cigarette or automobile fuel. The smoke resulting from the use of electrocautery is also a combustion product. The risk from electrocautery is not well understood in comparison to the coverage of risk from the aforementioned combustion products. VOCs were found in gas samples obtained from ten patients after the use of energized dissection (electrocautery) in one study, and the researchers found that known carcinogens and irritant hydrocarbons such as benzene, ethylbenzene, styrene, toluene, heptene, and methylpropene were present in gas samples at low concentrations [21]. Formaldehyde is also a known human carcinogen that medical personnel are routinely exposed to [3]. 
Our study did not detect any VOCs (benzene and toluene). The limit of detection of the analysis method (reporting limit) for benzene and toluene was 0.0010 and $0.0100 \mathrm{mg}$, respectively. The detected formaldehyde level was well below the Occupational Safety and Health Administration (OSHA) mandated permissible exposure limit of 0.75 parts per million parts of air for an 8-hour time-weighted average. The limit of detection of the analysis method (reporting limit) was $0.050 \mu \mathrm{g} / \mathrm{sample}$.

Electrocautery produces particles with aerodynamic sizes as small as $0.07 \mu \mathrm{m}$. This is even smaller than the particles produced during laser ablation [2, 3, 9, 22]. These ultrafine particles can travel long distances from their production site up to $100 \mathrm{~cm}$ [9]. Particles smaller than $10 \mu \mathrm{m}$ are inhalable and can be deposited in the respiratory tract. The majority of the fine particles are cleared by mucocilliary response but particles smaller than $2.5 \mu \mathrm{m}$ can penetrate deeper in the lungs, enter alveoli and may induce pro-thrombotic responses. On-going pro-thrombotic responses can lead to atherosclerosis and thrombogenesis $[6,22]$. We observed that the concentration of PM 2.5 increased significantly during the duration of the use of electrocautery. The mean concentration of PM 2.5 during the active phase of the use of electrocautery was $795 \mu \mathrm{g} / \mathrm{m}^{3}$. It was far greater than the mean concentration measured during background as well as post-exposure periods. The mean concentration during each use of electrocautery (exposure peak) was even much higher than the mean concentration for the total exposure period, at times the levels reached as much as $26,590 \mu \mathrm{g} / \mathrm{m}^{3}$. These results convey that high levels of PM 2.5 were generated during electrocautery use. However, the PM 2.5 concentration was reduced and cleared rapidly when the electrocautery was not in use. The low-level concentration values during post-exposure period is indicative of return to background levels in a timely manner, likely due to the efficient ventilation system in operation room. Surgical smoke evacuators were not in place during surgery.

From the survey, we found that the surgeons preferred open procedures over laparoscopic procedures. The extent of exposure of surgical smoke tends to be different in both procedures of surgery. In open surgery, use of smoke aspirators can reduce the exposure of smoke by $98 \%$ when placed one centimeter from the operation site. However, when the smoke aspirator is moved two centimeters from the operation site, the efficacy of smoke evacuators decreases by $50 \%$ [3]. Practically, it is not always possible to place the smoke evacuators in such close proximity with the treatment site. In this situation, it is best advisable to improve engineering controls such as exhaust systems.

Most surgeons reported that, on average, they used cautery from 21 to 40 times during surgery. Some reported use of cautery less than 20 times. The frequency of the use of the cautery varies with the requirement of the procedure. Typically, the frequency is higher during major procedures and involves large tissue resection.

Many by-products in the surgical smoke lead to adverse pulmonary outcomes such as emphysema, bronchiolitis, and alveolar congestion [9]. Over one-fifth of the surgeons in our study had asthma. While our questionnaire did not attempt to decipher the origin of the disease between occupational and other causes, it was useful to report an important finding of the high frequency of asthma. Other studies have also reported similar results. In one study, the prevalence of asthma was $10.9 \%$ and was almost double the asthma prevalence for the general population of the United States [23]. In another study, authors reported that the likelihood of severe and persistent form of asthma was more than double among operation room nurses compared to that among administrative nurses [24]. These reports further highlight the importance of having an efficient surgical smoke management system in the operation room.

Spread of infection of microorganisms from surgical smoke has been well known $[9,22,25,26]$. In our survey, at least one surgeon

$\mathrm{J}$ Pub Health Issue Pract

Volume 4. 2020. 172 reported an HPV infection from laser plume exposure from the pool of 43 respondents. Primarily, the cases of HPV infection were reported as case studies. But consistent findings of HPV virus isolation from the surgical smoke in recent times warrant the investigation of transfer of infection of HPV and other viruses from the patients to the surgery staff via surgical smoke.

Benzene is an important concern surgical smoke exposure. Benzene can cause short-term effects such as headache and irritation of eyes, nose and respiratory tract [3]. In our survey, nearly a quarter of the responding surgeons reported eye irritation due to surgical smoke exposure.The high frequency of benzene-related symptoms due to exposure of surgical smoke is important concern and further advocates the need of control of the smoke in the operation room.

In our survey, the most prominent symptoms from electrocautery use were reported as eye irritation and headache. Our findings are similar to those from other studies. Headache was the most prominent symptom reported in a survey administered among 36 doctors (surgeons and anesthesiologists) and 45 nurses (scrub and circulating nurses) [27]. Watery eyes and cough were the second most commonly reported symptoms among doctors and nurses in this survey, respectively. In a study from Mexico, the surgery and anesthesiology residents reported eye irritation as the most frequently experienced symptom [28]. Authors from a British study reported that operation room staff reported headache as the most prevalent symptom from electrocautery use [29]. These adverse health effects can be best managed by installing a high quality engineering controls.

In the review on the exposure of surgical smoke to dermatologists, Lewinet al. [30] mentioned that the studies reported low use of personal protective equipment. In our study over $90 \%$ of the responding surgeons reported that they always used of surgical masks, gloves and gowns. However, the use of other PPE such as eye protectors and smoke evacuators was lower $(64 \%)$. Also, studies reviewed by Lewin et al. [30] reported that only $5 \%$ of the surgeons used $\mathrm{N}-95$ respirators or other NIOSH approved respirator. This result was consistent with our study where $21 \%$ of the respondents reported seldom use of N-95 respirators. Regular surgical masks provide protection to particles of size of only $5 \mu \mathrm{m}$ and above [9]. In addition, surgical masks may not provide protection against disease causing microorganisms of size less than $5 \mu \mathrm{m}$. In our study, no surgeon's coughing and sneezing episodes during electrocautery use were seen. In any case, N-95 respirators can filter particles of size of as small as 0.3 micron [31]. These findings underline the importance of raising the awareness about the use of exposure controls, specifically smoke evacuators and N-95 respirators. Efforts to find even more efficient PPE are in process. According to Gao et al. [32], N100 facepiece respirator (prototype) showed some promise of better protection against exposure to surgical smoke compared to the protection from using N-95 respirators.

The strengths of this study include an efficient study design that included a short but succinct survey coupled with high quality exposure monitoring. The results of the study were comparable to other studies. The study demonstrated high exposure to PM 2.5 in the operation field and explored the possibility of the association between occupational exposure of surgical smoke and adverse health outcomes.

There were some limitations. First, only one surgery event was monitored to study the exposure to surgical smoke. Secondly, as with any other occupational health studies, it was difficult to understand if the respiratory diseases in surgeons were due to occupational exposure of surgical smoke or due to other exposures such as tobacco products. Biological monitoring has some merit to explore this area but more investigation is required in terms of conceptual frame work. Thirdly, the media for factory calibration of the particulate sampling equipment (Arizona Road Dust) and the media for the study (95\% water) are different. Both media have different density and refractive indices which might have impacted the accuracy of PM 2.5 JPHIP, an open access journal ISSN- 2581-7264 
measurements. We did not perform gravimetric calibration of the PDR-1500 instrument specifically for surgical smoke. Finally, limited detection of formaldehyde and VOCs could have been attributed to employing passive badges. For future research, detection of these chemicals in the surgical smoke can be improved by using photoionization detectors.

\section{Implications for Safety Researchers}

The results from our study showed that surgeons are exposed to chemicals such as formaldehyde and PM 2.5 during surgery. Future studies can further explore the cause and effect relationship between these chemicals and the health of surgical staff using multiple and varied surgery monitoring sessions. We found that post-electrocautery use exposure was significantly low which is indicative of high quality ventilation systems. The efficacy of a good ventilation system can be further explored by future studies. This ultimately can be helpful to evaluate the efficiency and the need of smoke evacuation systems to control air pollution in surgical environments.

\section{Conclusion}

Surgical smoke can be potentially a hazardous exposure over certain amount of time. The extent of risk on the human health from the exposure of surgical smoke is not yet well defined. Our study showed high exposure of surgical smoke during the use of electrocautery. It also highlighted some health ailments in surgeons that may be caused or aggravated by the exposure of surgical smoke. The research on exposure of surgical smoke is still in its infancy. Future research efforts should be targeted to understand the extent of long term exposure of low and high level of surgical smoke and its pathological implications.

\section{Competing Interests: Authors have no competing interests. \\ References}

1. Andreasson S.N., Mahteme H., Sahlberg B., Anundi H. (2012). Polycyclic aromatic hydrocarbons in electrocautery smoke during peritonectomy procedures. Journal of Environmental and Public Health, 2012:929053, doi: 10.1155/2012/929053.

2. Karoo R. O., Whitaker I. S., Offer G., \& Sharpe D. T. (2004). Surgical smoke without fire: the risks to the plastic surgeon. Plastic and Reconstrctive Surgery, 114 (6),1658-60.

3. Lewin J.M., Brauer J.A., \& Ostad A. (2011). Surgical smoke and the dermatologist. Journal of American Academy of Dermatology. 65(3), 636-641.

4. Taravella M.J., Weinberg A., May M., \& Stepp P. (1999). Live virus survives excimer laser ablation. Ophthalmology, 106(8), 1498-1499.

5. Best S.R., Esquivel D., Mellinger-Pilgrim R., Roden R.B.S., Pitman M.J. (2019). Infectivity of murine papillomavirus in the surgical byproducts of treated tail warts. Laryngoscope, 130(3), 712-717, doi: 10.1002/lary.28026.

6. Sanderson C. (2012). Surgical smoke. Journal of Perioperative Practice, 22(4):122-128.

7. Edwards B.E., Reiman R.E. (2012).Comparison of current and past surgical smoke control practices. AORN Journal, 95(3):337-50.

8. U.S. Department of Labor. Occupational Safety and Health Administration. 2019. Laser/electrosurgery plume. Available from https://www.osha.gov/SLTC/laserelectrosurgeryplume/.

9. Barrett W.L., Garber S.M. (2013). Surgical smoke: a review of the literature. Surgical Endoscopy, 17(6):979-987.

10. Centers for Disease Control and Prevention. 2014. National Institute for Occupational Safety and Health. Control of smoke from laser/electric surgical procedures. DHHS (NIOSH) publication number 96-128.
11. Fencl J.L. (2017). Guideline Implementation: Surgical Smoke Safety. AORN Journal, 105 (5, 488-497.

12. SurveyMonkey. 2019. Available from https://www. surveymonkey.com.

13. SKC Ultra Passive Diffusive Sampler. 2015. Available from https:/www.skcltd.com/products2/passive-samplers/voc-575organic-vapour.html.

14. UMEX Diffusive Sampler. 2015. Available from https:// www.skcltd.com/products $2 /$ passive-samplers/umex-100formaldehyde.html\#sampling-rates-for-other-aldehydes.

15. Ojima J. (2012). Gaseous contaminant distribution in the breathing zone. Industrial Health, 50(3):236-238.

16. National Institute for Occupational Safety and Health Manual of Analytical Methods-VOCs 2016. Available from https://www. cdc.gov/niosh/docs/2003-154/pdfs/2549.pdf.

17. National Institute for Occupational Safety and Health Manual of Analytical Methods-Formaldehyde. 2016. Available from https://www.cdc.gov/niosh/docs/2014-151/pdfs/methods/2016. pdf.

18. MIE pDR-1500 Active Personal Exposure Monitor Instruction Manual. 2014. Available fromhttp://tools.thermofisher.com/ content/sfs/manuals/EPM-manual-PDR1500.pdf.

19. Statistical Analysis System. 2019. Version 9.3. Available from http://support.sas.com/software/93/.

20. Choi S.H., Kwon T.G., Chung S.K., Kim T. (2014). Surgical smoke may be a biohazard to surgeons performing laparoscopic surgery. Surgical Endoscopy, 28(8):2374-2380. doi: 10.1007/ s00464-014-3472-3.

21. Fitzgerald J.E., Malik M., Ahmed I. (2012) A single-blind controlled study of electrocautery and ultrasonic scalpel smoke plumes in laparoscopic surgery. Surgical Endoscopy, 26(2):337342.

22. Bruske-Hohlfeld I., Preissler G., Jauch K.W.,Pitz M., Nowak D., Peters A, et al. (2008). Surgical smoke and ultrafine particles. Journal of Occupational Medicine and Toxicology, 3, 3:31.

23. Ball K. (2010). Surgical smoke evacuation guidelines: compliance among perioperative nurses. AORN Journal. 2010, 92(2):e1-e23.

24. Le Moual N., Varraso R., Zock J.P., Henneberger P., Speizer F.E., Kauffmann F, et al. (2013). Are operating room nurses at higher risk of severe persistent asthma? The Nurses' Health Study. Journal of Occupational and Environmental Medicine, 55(8), 973-977.

25. Walczak D.A., Grobelski B., Pasieka Z. (2011). "There is no smoke without a fire"--surgical smoke and the risk connected with it. Polish Journal of Surgery. 2011, 1 ; 83(11),634-639.

26. Lester J.D., Hsu S., Ahmad C.S. (2012). Occupational hazards facing orthopedic surgeons. American Journal of Orthopedics, 41(3), 132-139.

27. Ilce A, Yuzden G.E., Yavuz van Giersbergen M. (2017). The examination of problems experienced by nurses and doctors associated with exposure to surgical smoke and the necessary precautions. Journal of Clinical Nursing, 26(11-12, 1555-1561.

28. Stanganelli N., Bieniek A., Margatho A., Galdino M., Barbosa K., Ribeiro R. (2019). Inhalation of surgical smoke: cohort of signs and symptoms in residents. ActaPaulista de Enfermagem, 32(4), 382-389.

29. Addley S., Quinn D. (2018). 1411 Surgical smoke risk - a survey of operating roomstaff. British Medical Journal, 75, A166. 
30. Lewin J.M., Brauer J.A., \& Ostad A. (2011). Surgical smoke and the dermatologist. Journal of American Academy of Dermatology. 2011, 65(3), 636-641.

31. U.S. Federal Food and Drug Administration. 2020. N95 respirators and surgical masks (face masks). Available from https://www.fda.gov/medical-devices/personal-protectiveequipment-infection-control/n95-respirators-and-surgicalmasks-face-masks.
32. Gao S., Koehler R.H., Yermakov M., \& Grinshpun S.A. (2016). Performance of facepiece respirators and surgical masks against surgical smoke: simulated workplace protection factor study. Annals of Occupational Hygiene, 60(5), 608-618. 